\title{
19
}

\section{From hand actions to speech: evidence and speculations}

\author{
Luciano Fadiga, Alice Catherine Roy, Patrik Fazio \\ and Laila Craighero
}

This paper reviews experimental evidence and presents new data supporting the idea that human language may have evolved from hand/mouth action representation. In favor of this hypothesis are both anatomical and physiological findings. Among the anatomical ones is the fact that the monkey homologue of human Broca's area is a sector of ventral premotor cortex where goals are stored at representational level. In this region neurons have been found that respond to action-related visual stimuli such as graspable objects (canonical neurons) or actions of other individuals (mirror neurons). Among the physiological findings are some recent ones by our group showing that (i) during speech listening the listener's motor system becomes active as if she were pronouncing the listened words; (ii) the transcranial magnetic stimulation (TMS)-induced temporary inactivation of Broca's region has no effects on either phonological discrimination or on phonological priming tasks; (iii) hand gestures where the hand is not explicitly visible (i.e. animal hand shadows) activate the hand-related mirror neuron system, including Broca's region; (iv) frontal aphasic patients are impaired in their ability to correctly represent observed actions. On the basis of these data we strengthen the hypothesis that human language may have evolved from hand action representation. We conclude by speculating that the property of recursion, considered peculiar to human language, may have been introduced to hand actions by the fabrication of tools. The addition of this property to our action system may represent a critical intermediate step during the development of human language.

\section{Introduction}

"Organs develop to serve one purpose, and when they have reached a certain form in the evolutionary process, they became available for different purposes, at which point the processes of natural selection may refine them further for these purposes." This sentence comes from Noam Chomsky and it is taken from a letter in the New York Review of Books (Chomsky, 1996, p. 41) in which stresses that he believes "language is part of shared biological endowment" and can be studied in the manner of other biological systems "as a product of natural selection." He claims, however, that "evolutionary theory has little to say, as of now, about such matters as language." 
In the present paper we will assume an evolutionary perspective in order to try to identify, by using Chomsky's words, the possible initial purpose at the basis of language evolution, and the organ which served that purpose.

The earliest attempts to localize the seat of language in the human brain were, perhaps not surprisingly, made by researchers in the field of phrenology, who located this faculty in the anterior part of the brain, bilaterally (Gall, 1822). This opinion would no doubt have disappeared along with the field of phrenology if it had not also found support in a series of experiments demonstrating that certain brain lesions abolish the ability of speech (aphasia), without destroying intelligence, and that these lesions are always located in the anterior lobes of the brain. It was Marc Dax who, during the early years of the nineteenth century, collected observations on aphasic patients and concluded that loss of language was preferentially associated with damage to the left half of the brain (see McManus, 2002). But it was Paul Broca who in 1861 began the study of the relationship between aphasia and the brain, by being the first to prove that aphasia was linked to specific lesions. The autopsy of his famous patient 'Tan' revealed that in his brain was present "a cavity with a capacity for holding a chicken's egg, located at the level of the fissure of Sylvius" (Broca, 1861). This area, a region that comprises the whole back part of the third frontal convolution, was later named Broca's area. Paul Broca made a very interesting remark regarding the deficits present in aphasics: “... which has perished in them, is therefore not the faculty of language, it is not the memory of words, it is not the actions of the nerves, ... it is the faculty of coordinated movements, responsible for spoken language." Thus, he stressed the importance of the process at the basis of the capacity to coordinate meaningless articulatory movements in order to finally obtain a meaningful word. A few years after Broca's first studies, Wernicke proposed the first theory of language, which postulated an anterior, motor speech centre (Broca's region); a posterior, semantic language centre (Wernicke's region); and a fibres tract, the arcuate fascicle, connecting the two regions (Wernicke, 1874).

The neurosurgeon Wilder Penfield was the first to demonstrate experimentally the involvement of Broca's region in speech production by electrically stimulating the frontal lobe in awake patients undergoing brain surgery for intractable epilepsy. This method had been set up to help delimiting, during the course of the surgical procedure, regions whose excision would lead to severe language impairment. Penfield collected dozens of cases and was the first to report that the stimulation of the inferior frontal gyrus evoked the arrest of ongoing speech, although with some individual variability. The coincidence between the focus of the Penfield effect and the location of Broca's area was a strongly convincing argument in favor of the motor role of this region (Penfield and Roberts, 1959).

However, cortical stimulation gave also a different version of Broca's area role in language processing. A series of experiments demonstrated that both Broca's and Wernicke's areas are implicated in both the comprehension and production aspects of language (Ojemann et al., 1989; Burnstine et al., 1990; Luders et al., 1991; Ojemann, 1992; Schaffler et al., 1993). In particular, Schaffler et al. (1993) reported on three patients with intractable focal seizures arising from the language-dominant left hemisphere. Arrays of subdural 
electrodes were placed over the left temporal lobe and adjacent supra-sylvian region. Electrical stimulation of Broca's area produced marked interference with language output functions including speech arrest, slowing of oral reading, paraphasia and anomia. However, the authors reported that at some sites in this region cortical stimulation also produced language comprehension deficits, particularly in response to more complex auditory verbal instructions and visual semantic material.

Earlier, Luria (1966) had noted that Broca's area patients made comprehension errors in syntactically complex sentences such as passive constructions, but only when function words or knowledge of the syntactic structure were essential for comprehension. For instance, they had difficulty with the question "A lion was fatally attacked by a tiger. Which animal died?" Thus, again, the description of deficits caused by an interruption, either acute or chronic, of the activity in Broca's area underlines its involvement particularly when there is the necessity to combine single elements in order to extract a particular meaning. This description is in line with brain-imaging studies indicating that in language comprehension Broca's area is mainly activated during processing of syntactic aspects when higher levels of linguistic processing are required (see Bookheimer, 2002 for a review). For example, Stromswold (1995) compared right-branching sentences (e.g. "The child spilled the juice that stained the rug") to the more difficult centre-embedded structures ("The juice that the child spilled stained the rug"), finding increased activity in Brodmann's area 44 (BA 44) for the more complex constructions. Subsequently, Caplan et al. (1998) used the same stimuli as Stromswold (1995) and they again found that the focus of activity was in Broca's area. In a second experiment, they varied the number of propositions in sentences ("The magician performed the student that included the joke" versus "The magician performed the stunt and the joke"). In this experiment, differences were found only in temporal lobe regions, not in Broca's. Caplan et al. (1998) argue that in the latter experiment, the increased memory load is associated with the products of sentence comprehension, whereas in the former experiment, the load is with the "determination of the sentence's meaning", by stressing again the peculiar role of Broca's region in combining elements to obtain a final result.

The role of Broca's area in perception processing is not limited to the domain of speech. Since the early 1970s several groups have shown a strict correlation between frontal aphasia and impairment in gesture/pantomime recognition (Duffy and Duffy, 1975, 1981; Gainotti and Lemmo, 1976; Daniloff et al., 1982; Glosser et al., 1986; Bell, 1994). It is often unclear, however, whether this relationship between aphasia and gesture recognition deficits is due to Broca's area lesion only or if it depends on the damage of other, possibly parietal, areas. In fact, it is a common observation that aphasic patients are sometimes affected by ideomotor apraxia too (see Goldenberg, 1996) probably because of the large extension of the territory perfused by the middle cerebral artery.

However, the story becomes increasingly complicated if we review all the recent brainimaging studies which report the activation of area 44/45 (see Fadiga et al., 2006b). One example is given by those studies that repeatedly observed activations of Broca's area (Mecklinger et al., 2002; Ranganath et al., 2003) while attempting to identify the neuronal substrate of the working memory. A series of papers by Ricarda Schubotz and 
Yves von Cramon investigated nonmotor and nonlanguage functions of the premotor cortex (for review see Schubotz and von Cramon 2003) and showed that premotor cortex is also involved in prospective attention to sensory events and in processing serial prediction tasks. Gruber et al. (2001) compared a simple calculation task to a compound one and once again observed an activation of Broca's area. In an elegant study, Maess et al. (2001) have further investigated the possibility that area 44 is involved in playing with rules by studying musical syntax. By inserting unexpected harmonics, Maess et al. (2001) created a sort of musical syntactic violation. Using magnetoencephalography (MEG) they studied the neuronal counterpart of hearing harmonic incongruity and they found an early right anterior negativity, a parameter that has already been associated with harmonics violation (Koelsch et al., 2000). The source of the activity pointed out BA 44, bilaterally.

\section{The monkey homologue of human Broca's area}

Thus, far from being exclusively involved in language-related processes, Broca's area seems to be involved in multiple tasks. At the same time it emerges from neuroanatomical studies that Broca's area, and in particular its pars opercularis, shares some cytoarchitectonic properties with the premotor cortices. Indeed, the granular cell layer (the IV cortical layer), which is clearly absent in BA 6, is only slightly present in BA 44. The frontal cortex becomes clearly granular only in area 45 , the pars triangularis of the inferior frontal gyrus. So, what is the common functional aspect of its activation? Our approach to unravel the question of the role of Broca's area will be an evolutionary one: we will step down the evolutionary scale in order to examine the functional properties of the homologue of BA 44 in our 'progenitors'. From a cytoarchitectonic point of view (Petrides and Pandya, 1997), the monkey's frontal area which closely resembles human Broca's region is an agranular/dysgranular premotor area (area F5 as defined by Matelli et al., 1985) (see Rizzolatti et al., 2002) (see Figure 19.1). More recently, Nelissen et al. (2005) and Petrides (2006) have focused their attention on the parcelization of monkey area F5. Although with some differences, both studies agree on the fact that the caudal bank and the fundus of the arcuate sulcus differ from one another as far as cytoarchitectonics are concerned. While the bank is mainly agranular, the fundus is dysgranular. Moreover, this last sector of area F5 remains clearly distinct from the contiguous anterior bank region that both studies consider as pertaining to prefrontal cortex.

We will now examine the functional properties of this area by reporting the results of experiments aiming at finding the behavioral correlate of single neuron response.

Microstimulation (Hepp-Reymond et al., 1994) and single neuron studies (see Rizzolatti et al., 1988) showed that in area F5 are represented hand and mouth movements. Most of the hand neurons discharge in association with goal-directed actions such as grasping, manipulating, tearing, and holding, while they do not discharge during similar movements when made with other purposes (e.g. scratching, pushing away). Furthermore, many F5 neurons become active during movements that have an identical goal regardless of the effectors used for attaining it, suggesting that those neurons are able to generalize the goal, independently from the acting effector. 


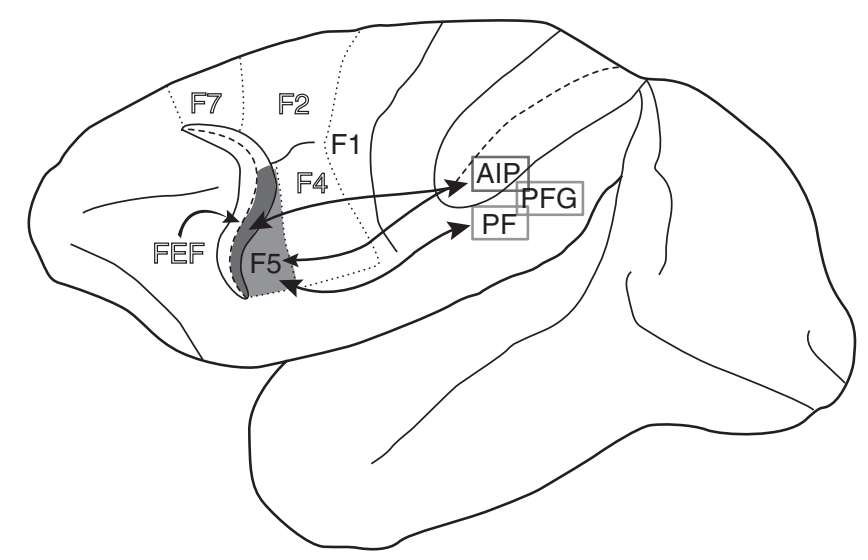

Figure 19.1 Lateral view of monkey left hemisphere. Area F5 is buried inside the arcuate sulcus (posterior bank, here in light blue) and emerges on the convexity immediately posterior to it (purple). Area F5 is bidirectionally connected with the inferior parietal lobule (areas AIP: anterior intraparietal, PF and PFG). Within the frontal lobe, area F5 is connected with hand/mouth representations of primary motor cortex (area F1), with sectors of area F2, with the mesial area F6 (not shown) and with prefrontal area $46{ }_{\Lambda}$

Using the action effective in triggering the neuron's discharge as classification criterion, F5 neurons can be subdivided into several classes: 'grasping', 'holding', 'tearing', and 'manipulating' neurons. Grasping neurons form the most represented class in area F5. Many of them are selective for a particular type of prehension such as precision grip, finger prehension, or whole hand prehension. By considering all the functional properties of neurons in this region, it appears that in area F5 there is a storage- $\mathrm{a}$ 'vocabulary' - of motor actions related to hand use. The 'words' of the vocabulary are represented by populations of neurons. Each indicates a particular motor action or an aspect of it. Some indicate a complete action in general terms (e.g. take, hold, and tear). Others specify how objects must be grasped, held or torn (e.g. precision grip, finger prehension, and whole hand prehension). Finally, some subdivide the action into smaller segments (e.g. finger flexion or extension).

All F5 neurons share similar motor properties. In addition to their motor discharge, however, several F5 neurons also discharge to the presentation of visual stimuli (visuomotor neurons). Two radically different categories of visuo-motor neurons are present in area F5: neurons of the first category discharge when the monkey observes graspable objects ('canonical' neurons; Rizzolatti et al., 1988; Rizzolatti and Fadiga, 1998). Neurons of the second category discharge when the monkey observes another individual making an action in front of it ('mirror' neurons; di Pellegrino et al., 1992; Gallese et al., 1996; Rizzolatti et al., 1996a). The two categories of F5 neurons are located in two different subregions of area F5: canonical neurons are mainly found in that sector of area F5 buried inside the arcuate sulcus, whereas mirror neurons are almost exclusively located in the cortical convexity of F5. 
When comparing visual and motor properties of canonical neurons it becomes clear that there is a strict congruence between the two types of responses. Neurons becoming active when the monkey observes small size objects, also discharge during precision grip. On the contrary, neurons selectively active when the monkey looks at a large object discharge also during actions directed towards large objects (e.g. whole hand prehension) (Murata et al., 1997). The most likely interpretation for visual discharge in these visuomotor neurons is that, at least in adult individuals, there is a close link between the most common three-dimensional (3D) stimuli and the actions necessary to interact with them. Thus, every time a graspable object is visually presented, the related F5 neurons are addressed and the action is 'automatically' evoked. Under certain circumstances, it guides the execution of the movement; under others, it remains an unexecuted representation of it, that might be used also for semantic knowledge.

Mirror neurons, which become active when the monkey acts on an object and when it observes another monkey or the experimenter making a similar goal-directed action, appear to be identical to canonical neurons in terms of motor properties, but they radically differ from them as far as visual properties are concerned (Rizzolatti and Fadiga, 1998). In order to be triggered by visual stimuli, mirror neurons require an interaction between a biological effector (hand or mouth) and an object. The sights of an object alone, of an agent mimicking an action, or of an individual making intransitive (nonobjectdirected) gestures are all ineffective. The object significance for the monkey has no obvious influence on mirror neuron response. Grasping a piece of food or a geometric solid produces responses of the same intensity. Typically, mirror neurons show congruence between the observed and executed action. This congruence can be extremely strict, that is the effective motor action (e.g. precision grip) coincides with the action that, when seen, triggers the neurons (e.g. precision grip). For other neurons the congruence is broader. For them the motor requirements (e.g. precision grip) are usually stricter than the visual ones (any type of hand grasping) (Gallese et al., 1996).

It seems plausible that the visual response of both canonical and mirror neurons addresses the same motor vocabulary, the words of which constitute the monkey motor repertoire. What is different is the way in which 'motor words' are selected: in the case of canonical neurons they are selected by object observation, in the case of mirror neurons by the sight of an action. Thus, in the case of canonical neurons, vision of graspable objects activates the motor representations more appropriate to interact with those objects. In the case of mirror neurons, objects alone are no longer sufficient to evoke a premotor discharge: what is necessary is a visual stimulus describing a goal-directed hand action in which both an acting hand and a target must be present.

Summarizing the evidence presented above, the behavioral conditions triggering the response of neurons recorded in the monkey area that is more closely related to human Broca's (ventral premotor area F5) are: (1) grasping with the hand and grasping with the mouth actions; (2) observation of graspable objects; (3) observation of hand/mouth actions performed by other individuals. Moreover, the experimental evidence suggests that, in order to activate F5 neurons, executed/observed actions must be goal-directed. 
Does the cytoarchitectonic homology linking monkey area F5 with Broca's area correspond to some functional homology? Does human Broca's area discharge during hand/mouth action execution/observation too? Does it make difference, in terms of Broca's activation, if observed actions are meaningful (goal-directed) or meaningless? A positive answer to these questions may come from a series of brain-imaging experiments hereafter described.

\section{The human mirror neuron system: brain imaging}

Direct evidence of an activation of premotor areas during observation of graspable objects was provided by a positron emission tomography (PET) experiment (Grafton et al., 1997). Normal right-handed subjects were scanned during observation of $2 \mathrm{D}$ colored pictures (meaningless fractals) during observation of 3D objects (real tools attached to a panel) and during silent naming of the presented tools and of descriptions of their use. The most important result was that the premotor cortex became active during the simple observation of the tools. This premotor activation was further augmented when the subjects named the tool use. This result shows that, as is the case with canonical F5 monkey neurons, also in the absence of any overt motor response or instruction to use the observed stimuli, the presentation of graspable objects increases automatically the activity of premotor areas. A very recent PET study conducted by Grèzes and Decety (2002) indicated that the perception of objects, irrespective of the task required to the subject (judgment of the vertical orientation, motor imagery, and silent generation of the noun or of the corresponding action verb), versus perception of nonobjects, was associated with activation of a common set of cortical regions. The occipito-temporal junction, the inferior parietal lobule, the supplementary motor area (SMA)-proper, the pars triangularis in the inferior frontal gyrus (Broca's area), the dorsal and ventral precentral gyrus, were engaged in the left hemisphere. The ipsilateral cerebellum was also involved. These activations are consistent with the idea that the mere perception of objects automatically activates representations of possible object affordances and the motor plans associated with their execution.

PET and functional magnetic resonance imaging (fMRI) experiments, carried out by various groups, demonstrated that when the participants observed actions made by human arms or hands, activations were present in the ventral premotor/inferior frontal cortex (Grafton et al., 1996; Rizzolatti et al., 1996b; Decety et al., 1997; Grèzes et al., 1998; Iacoboni et al., 1999; Decety and Chaminade, 2003; Grèzes et al., 2003). Grèzes et al. (1998) investigated whether the same areas became active during observation of both transitive (goal directed) and intransitive meaningless gestures. Normal human volunteers were instructed to observe meaningful or meaningless actions. The results confirmed that the observation of meaningful hand actions activates the left inferior frontal gyrus (Broca's region), the left inferior parietal lobule plus various occipital and inferotemporal areas. An activation of the left precentral gyrus was also found. During meaningless gesture observation there was no Broca's region activation. Furthermore, in 
comparison with meaningful action observations, an increase was found in activation of the right posterior parietal lobule. More recently, two further studies have shown that a meaningful hand-object interaction is more effective in triggering Broca's area activation than pure movement observation (Hamzei et al., 2003; Johnson-Frey et al., 2003). Similar conclusions have also been reached for mouth movement observation (Campbell et al., 2001). For clarity reasons, it should be stressed here that the distinction meaningful/meaningless is just one possible interpretation. It is also possible that the differential involvement of the left/right inferior frontal gyri could be due to the effort made by participants in trying to find a meaning in the observed action.

Very recently (Fadiga et al., 2006a), we investigated the possibility that Broca's area becomes specifically active during the observation of a particular category of hand gestures: hand shadows representing animals opening their mouths. Hand shadows only implicitly 'contain' the hand creating them (i.e. hands are not visible but subjects are aware of the fact that the animals presented are done by hand). Thus, they are interesting stimuli that might be used to answer the question of how detailed a hand gesture must be in order to activate the mirror neuron system. The results support the idea that Broca's area is specifically involved during meaningful action observation and that this activation is independent of any internal verbal description of the observed scene. Moreover, they demonstrate that the mirror neuron system becomes active even if the pictorial details of the moving hand are not explicitly visible: in the case of our stimuli, the brain also 'sees' the performing hand behind the appearance. During the fMRI scanning, healthy volunteers ( $n=10$ ) observed videos representing (i) the shadows of human hands depicting animals opening and closing their mouths, (ii) human hands executing sequences of meaningless finger movements, or (iii) real animals opening their mouths. Each condition was contrasted with a 'static' condition, in which the same stimuli presented in the movie were shown as static pictures (e.g. stills of animals presented for the same period of time as the corresponding videos). In addition, to emphasize the action component of the gesture, brain activations were further compared between pairs of conditions in a block design. Figure 19.2 shows, superimposed, the results of the moving versus static contrasts for animal hand shadows and real animal conditions (red and green spots, respectively). In addition to largely overlapping occipito-parietal activations, a specific differential activation emerged in the anterior part of the brain. Animal hand shadows strongly activated left parietal cortex, pre- and postcentral gyri (bilaterally), and bilateral inferior frontal gyrus (BA 44 and 45). Conversely, the only frontal activation reaching significance in the moving versus static contrast for real animals was located in bilateral BA 6, close to the premotor activation shown in an fMRI experiment by Buccino et al. (2004) when subjects observed mouth actions performed by monkeys and dogs. This location may therefore correspond to a premotor region where a mirror neuron system for mouth actions is present in humans.

The results shown in Figure 19.2 indicate that the shadows of animals opening their mouths, although clearly depicting animals and not hands, convey implicit information about the human being moving her hand in creating them. Indeed, they evoke an activation pattern superimposable on that evoked by hand action observation (Grafton et al., 1996; 

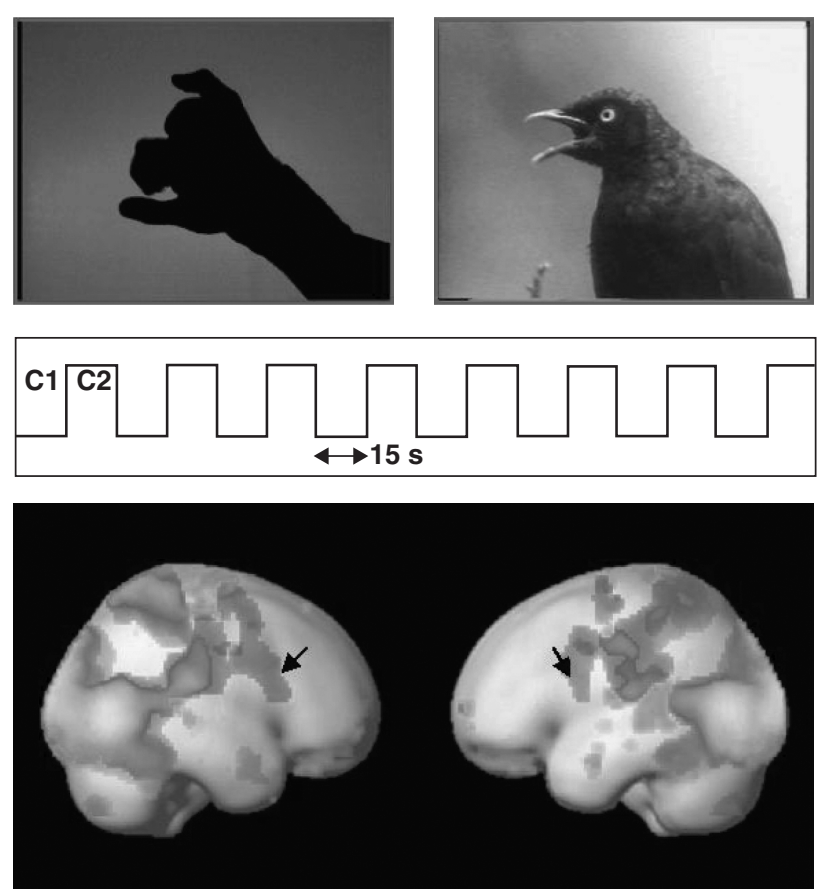

Figure 19.2 Cortical activation pattern during observation of animal hand shadows and real animals. Significantly activated voxels ( $p<0.001$, fixed effects analysis) in the moving animal shadow and moving real animal conditions after subtraction of the static controls. Activity related to animal shadows (red clusters) is superimposed on that from real animals (green clusters). Those brain regions activated during both tasks are shown in yellow. In the middle part of the figure, the experimental time-course for each contrast is shown (i.e. C1, moving; C2, static). Note the almost complete absence of frontal activation for real animals in comparison to animal shadows, which bilaterally activate the inferior frontal gyrus (arrows). (Modified from Fadiga et al., 2006a.). See color plate section.

Buccino et al., 2001; Grèzes et al., 2003). Consequently, the human mirror system (or at least part of it) can be seen more as an active interpreter than as a passive perceiver or resonator. Data from a recent monkey study (Umiltà et al., 2001), in which the amount of visual information in observed actions was experimentally manipulated, led to similar conclusions. Here the experimental paradigm consisted of two basic conditions. In one, the monkey was shown a fully visible action directed toward an object ('full vision' condition). In the other, the monkey saw the same action but with its final critical part hidden ('hidden' condition). Before each trial the experimenter placed a piece of food behind the screen so that the monkey knew that there was an object behind it. The main result of the experiment was that more than half of the tested neurons discharged in the hidden condition (see Figure 19.3). 

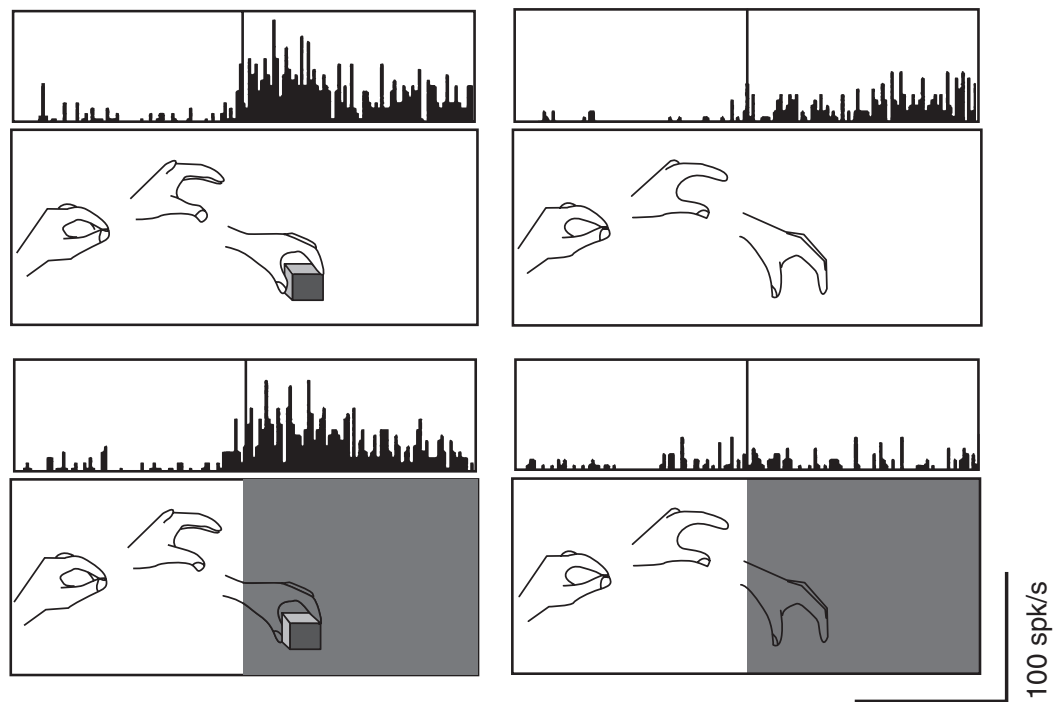

1s

Figure 19.3 F5 neuron responding to grasping observation in full vision and in hidden condition (leftmost two panels) but not in mimed conditions (rightmost two panels). The lower part of each panel illustrates schematically the experimenter's action. The grey square inside the panel represents the opaque screen that prevented the monkey from seeing the action that the experimenter performed behind it. There were two basic conditions: full vision condition, and hidden condition. Grasping actions were either actually performed or mimed (without object). In each panel, histograms of neuron discharge (10 consecutive trials) are shown. (Modified from Umiltà et al., 2001.)

\section{From hand actions to 'speech actions'}

Others' actions do not generate only visually perceivable signals. Action-generated sounds and noises are also very common in nature. One could also expect, therefore, that this sensory information, related to a particular action, could determine a motor activation specific for that same action. A very recent neurophysiological experiment addressed this point. Kohler et al. (2002) investigated whether there are neurons in area F5 that discharge when the monkey makes a specific hand action and also when it hears the corresponding action-related sounds. The experimental hypothesis was based on the observation that a large number of object-related actions (e.g. breaking a peanut) can be recognized by a particular sound. The authors found that $13 \%$ of the investigated neurons discharge both when the monkey performed a hand action and when it heard the action-related sound. Moreover, most of these neurons discharge also when the monkey observed the same action demonstrating that these 'audio-visual mirror neurons' represent actions independently of whether they are performed, heard or seen. 
Most recently, a brain-imaging study has revealed that perception of bilabial consonants (that recruited actively the lips to be pronounced) versus alveolar consonants (that, in contrast, recruited more actively the tongue) give rise to a somatotopic activation of the precentral gyrus (Pulvermuller et al., 2006). Previously, Fadiga et al. (2002), by using transcranial magnetic stimulation, had shed light on the motor resonance occurring while listening to words. They revealed that the passive listening to words that would involve tongue mobilization (when pronounced) induces an automatic facilitation of the listener's motor cortex. Indeed, the tongue motor-evoked potentials (MEPs), evoked by transcranial magnetic stimulation (TMS) of left tongue motor representation, reached higher amplitudes when Italian subjects were listening to Italian words that recruited important tongue movements (/birra/) when compared to words recruiting less important tongue movements (/buffo/). Furthermore, the effect was stronger in the case of words than in the case of pseudowords (Figure 19.4, left).

These findings strengthen the idea that language and fine motor skills may share a common origin, and further suggest that recognizing a verbal stimulus to be a word or not might differentially influence the motor cortex excitability. In a more recent study (Roy et al., unpublished data), we specifically addressed the hypothesis that the lexical status of a passively heard verbal item can selectively affect the excitability of the primary motor cortex of the tongue. Specifically, we aimed at answering two questions that were left

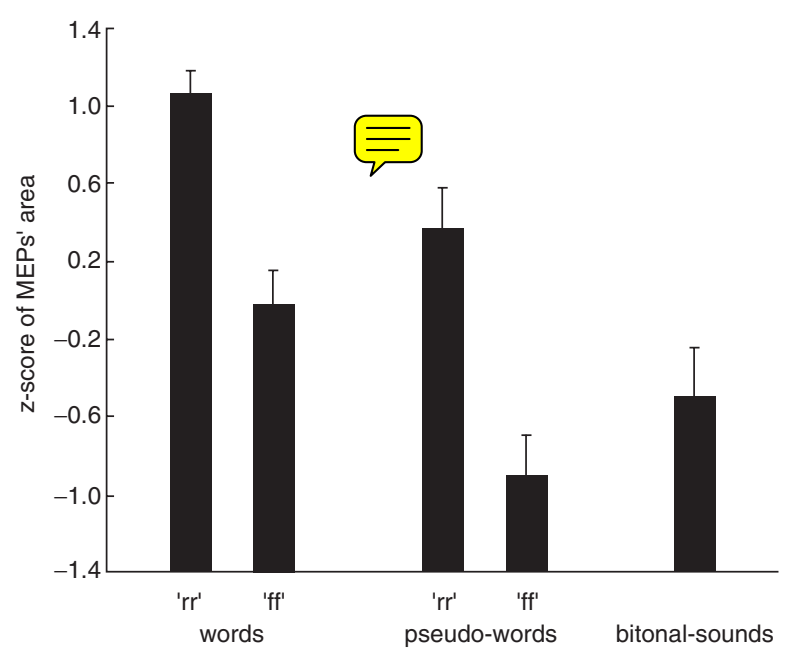

Figure 19.4 (Left) Average value ( \pm SEM) of intrasubject normalized motor-evoked potential (MEP) total areas for each condition (modified from Fadiga et al., 2002). Data from all subjects; ' $r r^{\prime}$ and ' $f f$ ' refer to verbal stimuli containing a double lingua-palatal fricative consonant $/ r$ /, and containing a double labio-dental fricative consonant/f/, respectively. (Right) Time-course of normalized MEP total area ( \pm SEM), as evoked by transcranial magnetic stimulation (TMS) on tongue motor representation at different timings during listening of frequent (dotted line) and rare (continuous line) words (Roy et al., unpublished data). 
unanswered by the previous study. On the one hand, the word versus orthographically regular pseudoword difference could be due to a familiarity effect, real words being more frequent than any pseudoword. On the other hand, one cannot exclude that, as words, pseudowords might yield to an effect analogous in amplitude, but delayed in time, on cortico-bulbar excitability. To shed further light onto these issues, we first sought to confirm and extend the phonological effect and then to disambiguate between the role of familiarity versus lexical status. To this aim, we recorded tongue MEPs by stimulating with TMS the left tongue motor representation, while subjects were passively listening to verbal stimuli (embedded with a double alveolar consonant i.e. /ll/) pertaining to three different classes: frequent words, rare words and pseudowords. During listening, we examined the time-course of motor cortex excitability by delivering single TMS pulses at four different time-intervals after the beginning of the double consonant $(0,100,200,300 \mathrm{~ms})$. Electromyogram potentials evoked by TMS were recorded as in Fadiga et al. (2002). During the experimental session, subjects were required to listen carefully to the presented stimuli and, to maintain their attention, to perform a lexical decision on the last heard stimulus (word or pseudoword?) at the occurrence of an instructional signal randomly presented. Three main results were obtained. First, by stimulating the tongue motor area at $120 \%$ of the motor threshold, we further replicated the phonological effect previously reported by Fadiga et al. (2002), as listening to verbal stimuli embedded with consonant recruiting significant tongue movements induced higher MEPs $(z$-score for $/ 11 /=0.187$; for non $/ 11 /=$ $-0.302 ; p<0.05)$. Second, we found that, with respect to uncommon words, frequent words yield to the smallest tongue MEPs. Third, this pattern varied according to the timing of the magnetic pulse: when the TMS pulse was applied at the very beginning of the consonant or $100 \mathrm{~ms}$ afterwards, the evoked muscle activity did not differ across stimulus class. From 100 to $200 \mathrm{~ms}$, the MEP area obtained for the rare words increased markedly (from -0.059 to 0.691 ). Then at $200 \mathrm{~ms}$ frequent words evoked the weakest tongue MEP while at $300 \mathrm{~ms}$ the difference between frequent and rare words was still present (Figure 19.4, right). Thus, the lexical status influenced the excitability of the primary motor cortex $200 \mathrm{~ms}$ after the beginning of the double consonant as rare words gave rise to the highest response.

Summarizing, these results indicate that the motor system is activated during speech listening. However, it is unclear if this activation could be interpreted in terms of an involvement of motor representations in speech processing and, perhaps, perception. This last possibility is in agreement with the idea originally proposed by Liberman (Liberman et al., 1967; Liberman and Mattingly, 1985; Liberman and Wahlen, 2000) starting from the perspective that sounds at the basis of verbal communication could be a vehicle for motor representations (articulatory gestures) shared by both the speaker and the listener, on which speech perception could be based. In other terms, the listener understands the speaker when her articulatory gestures/representations are activated by verbal sounds (motor theory of speech perception). In the next section, we will discuss this issue and we will present the results of some new experiments performed both on normal subjects and patients, that may help to clarify the role of frontal motor cortices in speech processing. 


\section{Is Broca's region involved in speech perception?}

Studies of cortical stimulation during neurosurgical operations and clinical data from frontal aphasics suggest that this is the case (see above). However, all these studies report that comprehension deficits become evident only in the case of complex sentence processing or complex command accomplishment. Single words (particularly if nouns) are almost always correctly understood. To verify this observation, we applied repetitive TMS (rTMS, that functionally blocks the stimulated area for hundreds of milliseconds) on speech-related premotor centers during single word listening (Fadiga et al., 2006b). Data analysis indeed showed that rTMS was ineffective in perturbing subjects' performance. A possible objection could be, however, that words, because of their lexical content, activate a complex network of areas, and thus the interruption of activity only in Broca's area is not sufficient to impair comprehension.

\section{Does TMS perturb phonological discrimination?}

On the basis of the previous results, we decided to use an experimental paradigm not involving words but meaningless pseudowords. Subjects were instructed to categorize a sequence of acoustically presented pseudowords according to their phonological characteristics, by pressing one among four different switches (L. Craighero, L. Fadiga and P. Haggard, unpublished data). Stimuli were subdivided into four different categories, according to the phonetic sequence of the middle part of the stimulus (/dada/, /data/, /tada/ or /tata/). Participants' left hemisphere was magnetically stimulated in three different regions by using rTMS: (a) the focus of the tongue motor representation, (b) a region $2 \mathrm{~cm}$ more anterior (ventral premotor/inferior frontal cortex), (c) a region $2 \mathrm{~cm}$ more posterior (somatosensory cortex). During the task, subjects had to listen to the presented stimulus and to press on a four-button keyboard (Figure 19.5c) the button identifying the middle
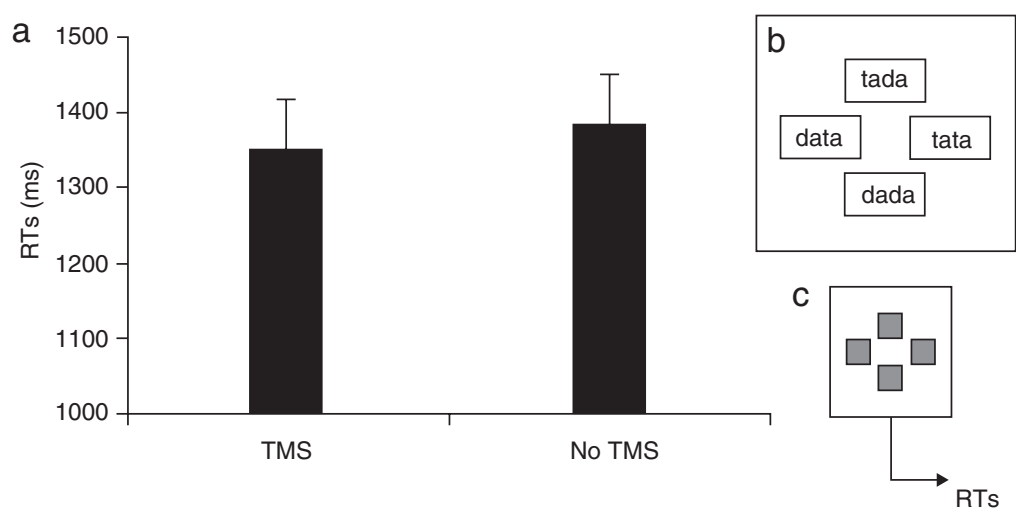

Figure 19.5 (a) Average value ( \pm SEM) of subjects' reaction times (RTs) during the phonological discrimination task described in the text. Note the absence of RT modulation depending on the administration of transcranial magnetic stimulation (TMS) on a point roughly corresponding to BA 44 (2 cm in front of tongue primary motor representation). (b and $\mathbf{c}$ ) The computer screen displayed to subjects and the keyboard for the response, respectively. 
part of the stimulus (e.g. /dada/). The correspondence between button and phonetic sequence was given by a four-picture display presented on a computer screen (Figure 19.5b) that was kept fixed for each subject but was counterbalanced across subjects. Repetitive TMS (120\% of individual motor threshold) was delivered at a frequency of $20 \mathrm{~Hz}$ in correspondence of the $2 \mathrm{nd}$ critical formant $(200 \mathrm{~ms})$, in correspondence of the 1st and of the 2nd critical formants $(200+200 \mathrm{~ms})$, and also during the whole critical portion of the presented word (600 ms). Results (Figure 19.5) showed no difference between the performances obtained during the different experimental conditions and for each stimulated site, neither in terms of errors nor for reaction times, demonstrating that rTMS was completely ineffective in perturbing phonological discrimination.

\section{Does TMS perturb the phonological priming effect?}

A possible interpretation of the absence of any effect of interference on phonologic discrimination might be that the discrimination task we used was either too simple or did not require a real phonologic processing because it might be accomplished by a simple acoustic discrimination of the serial order of two different (not necessarily phonologic) elements. For these reasons, we thus decided to use a 'phonological priming' task, a wellknown experimental paradigm based on the observation that a target verbal stimulus is recognized faster when it is preceded by a prime sharing with the target its last syllable

ED: Please provide table caption.

\section{Table 19.1}

\begin{tabular}{lllll}
\hline Prime trarget & Word-Word & $\begin{array}{l}\text { Word- } \\
\text { pseudoword }\end{array}$ & $\begin{array}{l}\text { Pseudoword- } \\
\text { word }\end{array}$ & $\begin{array}{l}\text { Pseudoword- } \\
\text { pseudoword }\end{array}$ \\
\hline Rhyming & Tocca-Bocca & Corta-Zorta & Losse-Tosse & Cata-Zata \\
& Pera-Cera & Freno-Preno & Vanze-Stanze & Buota-Suota \\
& Tango-Fango & Tasca-Masca & Comba-Bomba & Cobia-Robia \\
& Bolla-Folla & Tizio-Cizio & Muga-Ruga & Nago-Sago \\
& Vita-Gita & Rana-Mana & Ciggia-Spiaggia & Tasna-Masna \\
& Fato-Lato & Caso-Zaso & Reta-Meta & Ciato-Viato \\
& Duna-Luna & Magno-Pagno & Paso-Vaso & Stoca-Ruoca \\
& Fare-Mare & Vecchio-Lecchio & Rento-Lento & Dano-Viano \\
& Zucca-Mucca & Colpe-Molpe & Vugno-Pugno & Tecra-Gecra \\
& Fido-Nido & Toro-Soro & Vesta-Testa & Polta-Solta \\
Non rhyming & Bomba-Zebra & Grugno-Buota & Lufo-Lesta & Zangra-Gispia \\
& Cesto-Sugo & Tana-Nago & Stali-Letto & Fazo-Rasuo \\
& Fiume-Scuola & Media-Tasna & Raga-Dopo & Diase-Noste \\
& Gara-Ritmo & Strada-Terto & Troli-Moro & Copa-Lafria \\
& Lago-Guancia & Vela-Marto & Neca-Tetro & Zasta-Guotra \\
& Mano-Granchio & Moro-Troli & Porpo-Tino & Piusca-Rieta \\
Noia-Cielo & Freno-Tile & Gondo-Prato & Brona-Dasta \\
& Panno-Capra & Terme-Cagia & Revia-Piena & Zugra-Friepa \\
Specchio-Stalla & Truppa-Giarti & Marto-Vela & Vutra-Ligri \\
Topo-Patto & Ragno-Ligri & Zangra-Sedia & Tausa-Mifro \\
\hline
\end{tabular}


(rhyming effect, Emmorey, 1989). In a single-pulse TMS experiment we therefore stimulated participants' inferior frontal gyrus (BA 44) while they were performing a phonologic priming task. TMS was administered between the prime and the target. In this way, the noise produced by the TMS was not interfering with stimulus presentation. During the task, subjects were instructed to carefully listen to a sequence of acoustically presented pairs of verbal stimuli (disyllabic 'cvcv' or 'cvccv' words and pseudowords) in which final phonologic overlap was present (rhyme prime) or, conversely, not present. The pairs of presented stimuli pertained to four categories which differed for presence of lexical content in the prime and in the target.

Subjects $(n=8)$ were requested to make a lexical decision on the target by pressing one of two buttons (word/pseudoword) with their index or middle finger. The association between fingers and lexical property was counterbalanced across subjects. Each category contained both rhyming and nonrhyming pairs. In some randomly selected trials, we administered single-pulse TMS in correspondence of left BA 44 (Broca's region) during the interval $(20 \mathrm{~ms})$ between prime and target stimuli. To avoid mislocalization of the target brain region, each subject underwent MRI scanning, and the position of subject's scalp covering the pars opercularis of the inferior frontal gyrus (BA 44) was assessed by using neuronavigation software developed in our laboratory (see Figure 19.6). In brief, a 6-DOF electromagnetic tracker (Flock of Birds, Ascension Technology) was attached to subject's forehead by an elastic band to compensate for head movements, and three repere points (bilateral tragus and nasion) were located by pointing on them using a stylus equipped with a second tracker. Then, the same repere locations were identified on the subject's MRI, and the two coordinate systems, that of subject's head and that of MRI, were put in register. Finally, for each point identified by the stylus on subject's
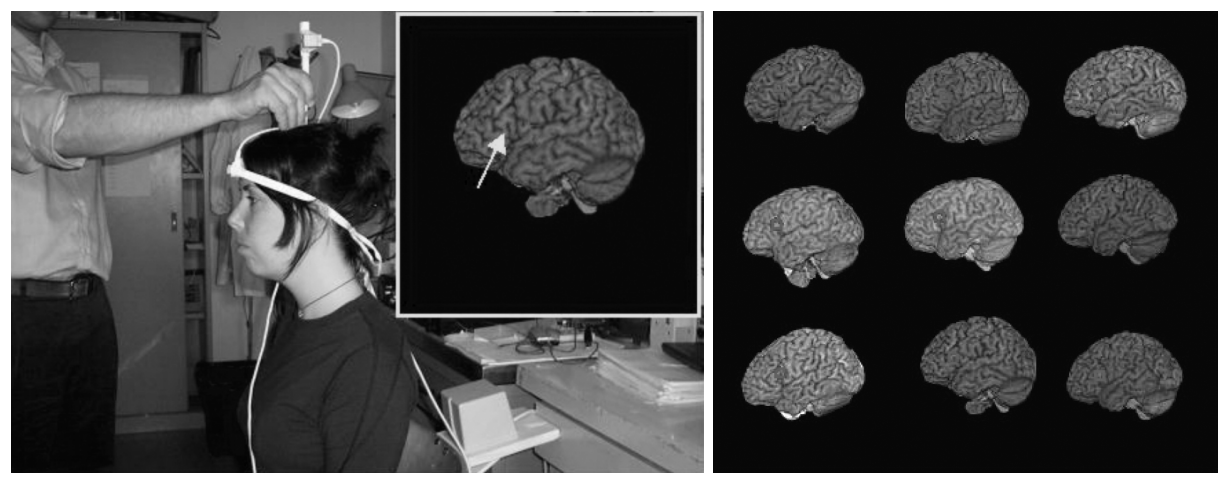

Figure 19.6 The procedure used in the phonological priming experiment to map individual Broca's areas. On the left, the electromagnetic tracking procedure is shown. For each subject, the center of pars opercularis of the inferior frontal gyrus was identified (yellow arrow). The panel on the right shows the three-dimensional reconstructed brain of nine subjects with a red circle superimposed indicating the location selected for administering transcranial magnetic stimulation during the experimental paradigm. See color plate section. 
scalp, the software gave in real time the corresponding three MRI sections passing from it (coronal, horizontal and sagittal).

A three-way repeated-measures analysis of variance (ANOVA) on reaction times with TMS administration (present, absent), priming effect (rhyming, non-rhyming pairs) and type of pairs (W-W, W-PW, PW-W, PW-PW) as within-subject variables was performed. It showed that priming effect $[F(1,7)=50,14, p<0.001]$ and type of pairs $[F(3,21)=13,75, p<0.001]$ were significant factors. Moreover, it showed significant interactions between TMS administration and type of pairs $[F(3,21)=5,98, p<0.01]$, between priming effect and type of pairs $[F(3,21)=13,95, p<0.001]$, and between TMS administration, priming effect, and type of pairs $[F(3,21)=3,37, p<0.05]$.

Newman-Keuls post hoc comparisons indicated that in trials without $\mathrm{TMS}_{k}$ there are three main results: (i) strong and statistically significant facilitation (phonological priming effect) when W-W, W-PW, PW-W pairs are presented; (ii) no phonological priming effect when the PW-PW pair is presented; (iii) faster responses when the target is a word rather than a pseudoword (both in $\mathrm{W}-\mathrm{W}$ and $\mathrm{PW}-\mathrm{W}$ ). An interesting finding emerges from the analysis of these results: the presence or absence of lexical content modulates the presence of the phonological priming effect. When neither the target nor the prime has the access to the lexicon (PW-PW pair), the presence of the rhyme does not facilitate the recognition of the target. In other words, in order to have a phonological effect it is necessary to have access to the lexicon.

In trials during which TMS was delivered ${ }_{R}$ only W-PW pairs were affected by brain stimulation: the W-PW pair behaving exactly as the PW-PW one. This finding suggests that the stimulation of Broca's region might have affected the lexical property of the prime. As consequence, the lack of access to the lexicon determines the absence of the phonological effect. According to our interpretation, the TMS-related effect is absent in the $\mathrm{W}-\mathrm{W}$ and $\mathrm{PW}-\mathrm{W}$ pairs because of the presence of a meaningful (W) target. Being aware that a possible criticism of our result is that the task was implying a lexical decision, we replicated the experiment by asking six new subjects to detect whether the final vowel of the target stimulus was /a/ or /o/. Despite the absence of any lexicon-directed attention,

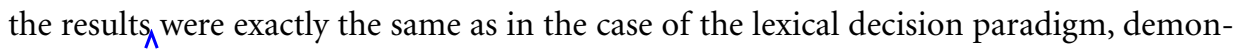
strating that the absence of phonological priming in the pseudoword/pseudoword pairs was independent of subject's task.

Independently from the main aim of the present study, that of interfering on perception by administering TMS, the unexpected finding that in the pseudoword/pseudoword pair the phonological priming effect is abolished, provokes at least two necessary considerations. First, the classical view stating that before attributing a lexical content, the brain decodes the phonology (two-step processing), seems not to be substantiated by our data. Second, the phonological priming effect appears to be not purely 'phonological' because it disappears if at least one of the two members of the pair is not characterized by a meaningful lexical content.

Our interpretation of these results is that it is impossible to dissociate phonology from lexicon and particularly at Broca's level because there 'exist' only words. Thus, phonologically relevant stimuli are matched on a repertoire of words and not on individually 
ED: Please update. meaningless 'phoneme assembly'. The original role played by the inferior fontal gyrus in generating/extracting action meanings might have been generalized during evolution, giving to this area the basics to build a new capability: a supramodal 'syntax' endowed with the ability to organize and comprehend hierarchical and sequential elements in meaningful structures. The motor resonance of tongue representation revealed by TMS during speech listening (RR/FF) is probably a mixed phenomenon. Cortical regions others than area BA $44\left(\mathrm{BA}_{\lambda} 6\right.$ ? ) might be involved in the "acoustically evoked mirror effect" (Fadiga et al., 2002) which is quite independent of the meaning of the presented stimuli. In this direction points the recent fMRI experiment by Wilson and colleagues (Wilson et al., 2004) showing that the only cortical region constantly activated during both listening and production of meaningless syllables was bilaterally located in the superior part of ventral premotor cortex, dorsal to BA 44 . However, it remains the fact that the lexical content of the listened words exerts a significant facilitation on primary motor cortex (M1) excitability (see Figure 19.4). It is likely that two distinct processes act on M1 at the same time: a meaning-independent one, which could be considered as the effect of a low-level motor resonance, and a lexical one, whose origin remains to be clarified by further experiments.

\section{Do frontal aphasics show deficits in motor syntax?}

What emerges from the temporary inactivation of Broca's area is that this area is not involved with purely phonological properties of the heard stimuli. The hypothesis we suggested in the previous section is that Broca's area, because of its premotor nature, could be involved in supramodal syntactic processing. If our hypothesis were true, we would expect that frontal aphasic patients suffering from lesion of Broca's region should, in addition to their classical symptoms in speech production and agrammatism, also show additional deficits in a more broadly 'motor' domain. In other words, people suffering from an inability to process syntax in the linguistic domain following frontal brain damage should be also impaired in another, motor, field, as long as supramodal syntactic skills are required. In particular, we hypothesized that the correlated defective domain would concern action. Tranel et al. (2003) also demonstrated that left frontal braindamaged patients have difficulty in understanding action details when shown cards depicting various action phases. However, in their study, the authors asked patients to answer verbally to verbally posed questions. It is therefore possible that patients may have had more problems in understanding the intimate content of the action-related questions than in representing actions themselves.

To better verify the hypothesis that nonfluent aphasia may be accompanied by deficits in action understanding, we designed an experiment in which Broca's aphasic patients were presented with a simple scrambled 'motor sentence' which they had to reorganize (P. Fazio et al., unpublished data). Patients were included in the study if they presented vascular lesions in the territory of the left middle cerebral artery, including the frontal inferior gyrus, and were diagnosed by a neuropsychologist as Broca's aphasics. Eleven patients met these initial enrolment criteria. All of them presented disorders of language production with agrammatic speech, while oral comprehension was largely preserved. 

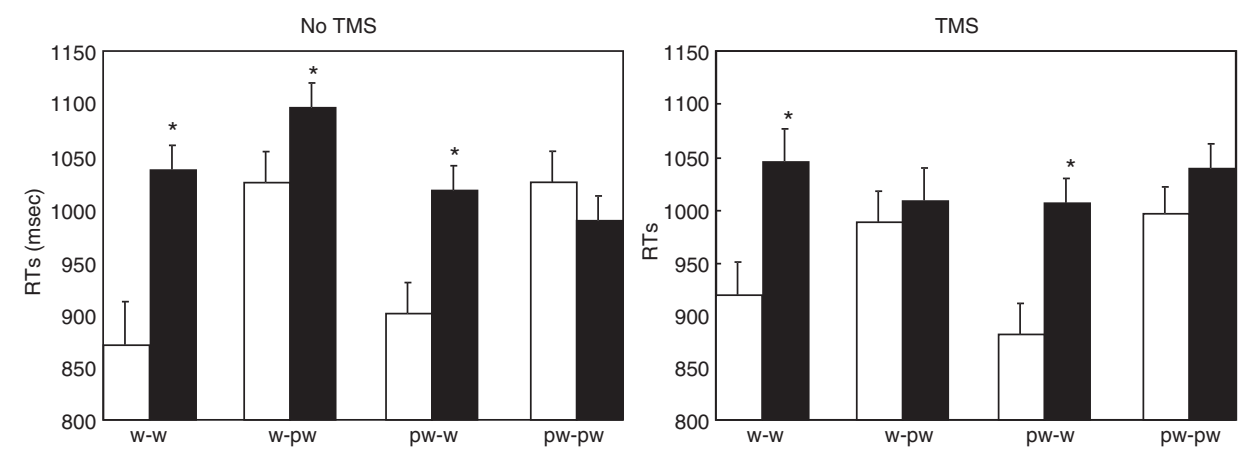

Figure 19.7 Reaction times (RTs \pm SEM in milliseconds) during the phonological priming task for the lexical decision, without (left panel) and with (right panel) transcranial magnetic stimulation (TMS) administration. White bars: presence of rhyme between prime and target. Black bars: absence of rhyme. Asterisks above black bars indicate the presence ( $p>0.05$, Newman-Keuls test) of a phonological priming effect (response to rhyming target faster than response to nonrhyming target) in the relative condition. TMS administration did not influence the accuracy of the participants, which was almost always close to $100 \%$. W-W, prime word/target word; W-PW, prime word/target pseudoword; PW-W, prime pseudoword/target word; PW-PW, prime pseudoword/target pseudoword.

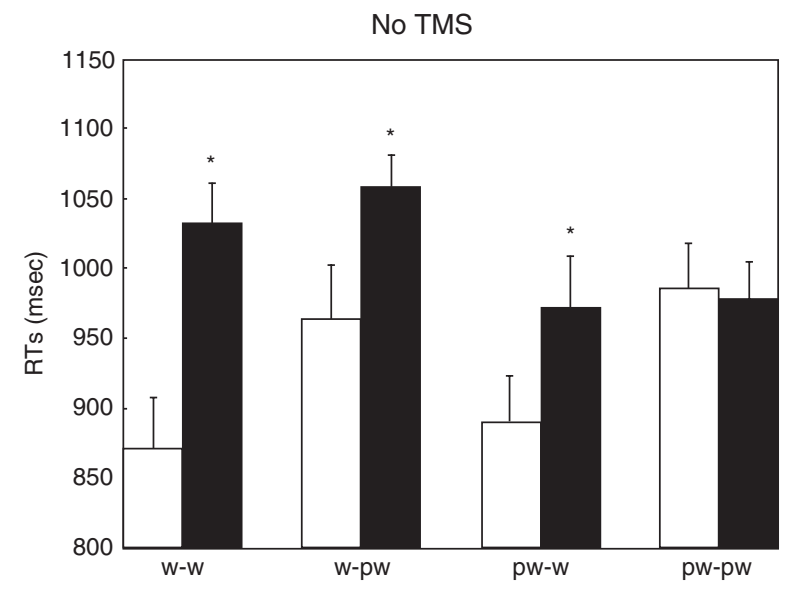

Figure 19.8 Reaction times (RTs \pm SEM in milliseconds) during the phonological priming task for the vowel discrimination task (no transcranial magnetic stimulation). Convention as in Figure 19.7.

Despite speech therapy, verbal fluency remained impaired at the time of the experimental investigation. Additionally, all 11 patients were screened to assess linguistic, praxic and general cognitive faculties and five patients suffering from apraxia have been successively excluded from the experimental testing. The experiment consisted of the presentation to each patient of 20 video clips, subdivided in two different classes: simple biological action (e.g. a hand grasping a bottle) and sequence of nonbiological moving object (e.g. a bicycle falling on the floor). After each video, patients were shown four snapshots taken 
from the video clip, randomly presented on a computer touch-screen; patients were then required to organize the frames so as to provide a meaningful order by touching the screen and by exchanging the position of the snapshot forming the sequence. As soon as they accomplished each trial, they had to press a validation button. We recorded and analyzed the accuracy and performance of the patient group and of a healthy control group, matching for age and instruction level.

A two-way repeated-measures ANOVA on reaction times, sequencing times, and accuracy, with Group (aphasics, controls) and Type of movement (biological, nonbiological) as within-subject variables was performed. It showed that Group was a significant factor for both reaction times $[t(1,5)=15.174, p<0.05]$ and sequencing times $[t(1,5)=17.025$, $p<0.01]$, indicating that aphasics were significantly slower than matched controls. The interaction between Group and Type of movement was not significant. As far as accuracy is concerned no main factors were significant but the interaction showed a tendency to significance $[t(1,5)=5.85, p=0.06]$. A two-tailed paired $t$-test $(a=0.05)$ indicated that controls showed no difference in accuracy between biological $(87 \pm 3 \%)$ and nonbiological movements $(77 \pm 6 \%)$, while aphasics performed significantly worse when they had to organize biological movements $(65 \pm 11 \%)$ with respect to nonbiological ones $(80 \pm 10 \%)$ (see Figure 19.9).

It is notable that this difference was specific for videos representing human actions since all patients were able to order other kinds of sequences, such as numbers. The difference in performance of patients between the two tasks is hardly compatible with a higher difficulty level of sequences representing human actions. Indeed, it took on average the same time for patients to perform the human and the nonbiological trials, whereas for healthy control subjects the opposite tendency prevails (more errors with nonbiological motion). Furthermore, the distribution of nonbiological motion trials in terms of sequencing time (i.e. difficulty) was coincident with that of human action trials.

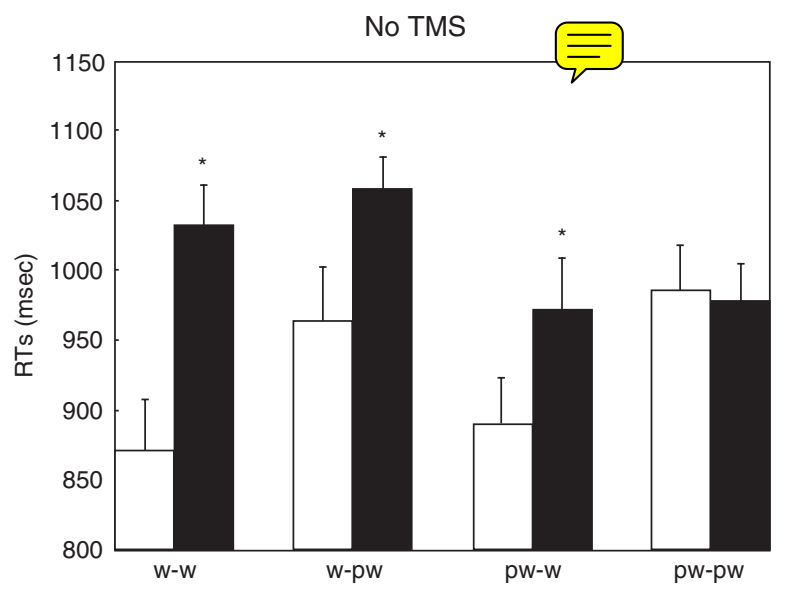

Figure 19.9 Percentages of correct trials (mean \pm SEM) in frontal aphasic patients and in normal subjects matched for age, educational attainment and gender, during the sequencing task. Asterisk indicates the presence of a statistically significant difference in the performance of the sequencing task (see text). 
Finally, as an additional control for the presence of syntactic deficits in a similar task but in the language domain, the patients were required to reorganize four tokens, each containing word pieces of a phrase, to compound a meaningful sentence (e.g. I turn - the key - and open - the door). They only reached $58 \%$ of accuracy in the latter task, thus confirming their profound agrammatism.

Although preliminary, these results are promising as they indicate a common impairment in syntactically organizing linguistic and motor material which, in the motor domain, is specific for biological motion, as a much better performance was observed with a sequential, nonbiological material. One could argue that this difference might depend on the biological versus nonbiological nature of the material. In this respect, brain-imaging studies have demonstrated that the observation of biological motion activates the premotor cortex, damaged in the tested population of patients, whereas nonbiological movement depends on a more posterior region (Grèzes et al., 2001; Saygin et al., 2004). However, the patients were presented with still frames that suggested, but never showed, real motion or movement. Moreover, our results are in accordance with previous studies showing that patients with lesions of Broca's area are impaired in learning the hierarchical, but not the temporal, structure of sequential tasks (Dominey et al., 2003, 2006). In the same vein, a study using event-related fMRI recently succeeded in disentangling hierarchical processes from temporal nested elements (Koechlin and Jubault, 2006). The authors reported that Broca's area and its right homologue control the selection and nesting of action segments integrated in hierarchical behavioral plans, regardless of their temporal structure. With respect to language, Broca's area is believed to process syntax, which is not a temporal sequence of words, but precisely a hierarchical structure defining the links between words. Therefore, our results add to the growing literature on the role of Broca's region. They strongly support Broca's role in processing a supramodal syntax which derives from the structure at the basis of action representation, which is embedded in the motor system. It is important to stress here that we are not dealing with the evocative capability of human language nor with its powerful capacity for generating/evoking abstract concepts. What we are interested in is the manner in which the verbal message is transmitted between the speaker and the listener, and in which syntax (at least in its canonical form) represents the set of rules allowing this transmission with efficacy.

\section{Conclusions}

At the beginning of this chapter we formulated the hypothesis that, in agreement with experimental findings on monkeys and humans, there should have been a common evolutionary pathway linking hand/mouth action representation and verbal communication. In general terms, this hypothesis is not new. For many years, several authors (Rizzolatti and Arbib, 1998; see Corballis, 2003) have proposed that human language may have been evolved from hand actions/gestures more than from the vocal call system, already present in inferior primates. Indeed, a gestural origin may account for some peculiarities of the human language (such as its combinatorial nature and the typically dyadic communicative process) that are absent in the directed-to-the-group and iconic 
vocal call system. Here, we have reviewed direct evidence in favor of an involvement of the motor system in speech processing, and have offered a reinterpretation of experimental evidence that may be summarized as follows.

Broca's area, the frontal region for speech production, is a premotor area, evolutionarily linked to a sector of monkey ventral premotor cortex (area F5a) where hand/mouth actions are represented. What characterizes these representations in the monkey cortex is (i) the presence of a goal, (ii) their organization in terms of vocabulary of actions, very often effector independent (e.g. grasping a small object with the right hand, with the left hand and with the mouth), (iii) their involvement in perception of similar actions performed by others, thanks to widely distributed visuo-motor properties.

Broca's area is involved in speech processing, not only during production but also during perception. This involvement is mainly at the sentence level (not at the word level) and it is positively correlated with the complexity of the sentences to be processed.

Broca's area becomes active in several nonspeech tasks having in common a syntactically organized structure (rhythms, music, mathematics, and complex sequences of actions). These domains share with speech the presence of rules that govern them in nonambiguous ways. In other words, they all deal with sequences organized according to a precise hierarchical structure.

This last point peculiarly emphasizes, in our view, the parallelism between speech and action representations. Indeed, both processes are organized in hierarchical structures hosting, when necessary, nested subroutines. Motor and speech sequences become significant because of the presence of the goal. Otherwise they remain meaningless assemblies of movements - in the case of actions, of words-in the case of sentences, or even of phonemes, in the case of single words. The glue linking the individual parts of a sequence in a meaningful way is in fact the goal of the action sequence.

In this light, the capacity of Broca's area to deal with sequences, not strictly speechrelated, has been proposed by several investigators on the basis of the evidence that this region is constantly involved in processing rhythms, music, and complex actions (see the paradigmatic experiment by Gelfand and Bookheimer, 2003). In addition, the ventral part of BA 6 (vBA 6 or PMv, ventral premotor), bordering with Broca's region, is highly specialized in motor/abstract sequence processing, as shown by the seminal work by Schubotz and colleagues (Schubotz and von Cramon, 2003, 2004; Schubotz et al., 2004; Wolfensteller et al., 2004). Very recently, Fiebach and Schubotz (2006) have proposed a unifying theory that takes into account the experimental findings regarding ventral premotor cortex and Broca's area. Their belief is that the ensemble vBA 6-BA 44 may be considered "a highly flexible sequence processor, with the PMv mapping sequential events onto stored structural templates and Broca's area involved in more complex, hierarchical or hyper-sequential processing." Friederici (2006) approaches a similar conclusion: "While BA 44/45 is seen to be increasingly activated whenever the internal re-construction of a hierarchical structure from a sequential input is necessary, BA 6 is involved in the processing of local structural dependencies." Finally, Grewe et al. (2006) add new evidence to the hypothesis that linguistic functions of Broca's region, and more specifically of the pars opercularis, may depend on a 'suprasyntactic' role, as suggested by the fMRI 
evidence that the violation of a linearization principle that is purely semantic in nature (animate arguments should precede inanimate arguments) increases the activation of pars opercularis.

What we add to this theoretical framework here is the idea that speech is represented in Broca's region not because this part of the brain has developed for this specific purpose but because, in our progenitors, it was already the part of the brain where goals - and the hierarchically organized motor chains planned to achieve those goals-are represented (see Fogassi et al., 2005). Therefore, the involvement of Broca's region in verbal communication could be provocatively considered an occasional 'epiphenomenon', motivated by its premotor origins. Consequently, forms of communication other than the verbal one, expressions of more ancient mechanisms, involve Broca's area because of its twofold involvement with motor goals: during execution of one's own actions and during perception of others' actions.

Several steps along this (putative) evolutionary pathway linking action representation (mainly hand actions) to linguistic syntax remain to be clarified, e.g. how object manipulation, introspectively driven, might have been transformed into communicative gestures. This passage has been considered a necessary prerequisite by several authors. It is possible, in our view, that the activity of the mirror neurons in the observer's brain, while looking at actions performed by another individual, may have contributed to the self-other distinction necessary to communicate. Moreover, as soon as our progenitors realized that their own actions were influencing the actions of others, the 'spark' may have appeared in their mind: the first nucleus of the dyadic, explicit communication.

Another issue, deserving particular consideration, is that raised by Fitch et al. (2005) in a recent paper on the origin of language. One of the points they make is that human language is exquisitely human because animal communication lacks the property of recursion, i.e. the ability to combine discrete elements (words) in an infinite variety of possible expressions. If one adopts this theoretical assumption, it follows that language may hardly have evolved from hand actions. Indeed actions are nonrecursive by definition: one cannot eat a piece of apple before grasping it.

There is, however, another possibility that may shed light on this intriguing puzzle which, as far as we know, has never been prompted before now. Linguists are familiar with the idea, originally proposed by Leroy-Gourhan (1964), that the appearance during evolution of the ability to make and use tools may have been the intermediate step linking action representation with human language. Here we propose the hypothesis that tool fabrication may have supplied action representation with the capability of recursion. Indeed, tool design and tool use expand the complexity of motor plans and project actions in temporal dimensions other than the present. This is particularly true in the case of tools fabricated to build other, new tools, which, in turn, would force the brain to postpone the ultimate goal following a complex, but quite flexible, hierarchy of subroutines/subgoals. These increased spatial-temporal degrees of freedom might have provided the brain with the first example of recursion of actions.

We believe that the discussion of this possibility could represent a fertile background for the interaction between linguistics and neuroscience, which represents 
an excellent approach to the study of language development in a multidisciplinary, convergent way.

\section{Acknowledgments}

This work has been supported by Italian MIUR, FCR and European Commission grants (Contact, Robot-cub and Neurobotics) to L.F. and L.C. and by the European Science Foundation OMLL Eurocores. We thank Rosario Canto for continuous support, Thierry Pozzo for providing us with the software for the experiment on aphasic subjects, Anna Cantagallo and Ferdinando Calzolari for their help with patients.

\section{References}

Bell, B. D. (1994) Pantomime recognition impairment in aphasia: an analysis of error types. Brain and Language, 47, 269-278.

Bookheimer, S. (2002) Functional MRI of language: new approaches to understanding the cortical organization of semantic processing. Annual Review of Neuroscience, 25, 151-188.

Broca, P. (1861) Remarques sur le Siége de la Faculté du Langage Articulé, Suivies d'une Observation d'aphemie (Perte de la Parole). Bulletin de la Société Anatomique de Paris, 6, 330-357.

Buccino, G., Binkofski, F., Fink, G. R. et al. (2001) Action observation activates premotor and parietal areas in a somatotopic manner: an fMRI study. European Journal of Neuroscience, 13, 400-404.

Buccino, G., Lui, F., Canessa, N. et al. (2004) Neural circuits involved in the recognition of actions performed by nonconspecifics: an FMRI study. Journal of Cognitive Neuroscience, $16,114-126$.

Burnstine, T. H., Lesser, R. P., Hart Jr J. et al. (1990) Characterization of the basal temporal language area in patients with left temporal lobe epilepsy. Neurology, 40, 966-970.

Campbell, R., MacSweeney, M., Surguladze, S. et al. (2001) Cortical substrates for the perception of face actions: an fMRI study of the specificity of activation for seen speech and for meaningless lower-face acts (gurning). Cognitive Brain Research, 12, 233-243.

Caplan, D., Alpert, N. and Waters, G. (1998) Effects of syntactic structure and propositional number on patterns of regional cerebral blood flow. Journal of Cognitive Neuroscience, 10, 541-552.

Chomsky, N. (1996) Language and evolution. (Letter.) New York Review of Books, 1 February, p. 41.

Corballis, M. C. (2003) From mouth to hand: gesture, speech, and the evolution of right-handedness. Behavioral and Brain Sciences, 26, 198-208.

Daniloff, J. K., Noll, J. D., Fristoe, M. and Lloyd, L. L. (1982) Gesture recognition in patients with aphasia. Journal of Speech and Hearing Disorders, 47, 43-49.

Decety, J. and Chaminade, T. (2003) Neural correlates of feeling sympathy. Neuropsychologia, 41, 127-138.

Decety, J., Grèzes, J., Costes, N. et al. (1997) Brain activity during observation of actions: Influence of action content and subject's strategy. Brain, 120, 1763-1777.

Di Pellegrino, G., Fadiga, L., Fogassi, L., Gallese, V. and Rizzolatti G (1992) Understanding motor events: a neurophysiological study. Experimental Brain Research, 91, 176-180.

Dominey, P. F., Hoen, M., Blanc, J. M. and Lelekov-Boissard, T. (2003) Neurological basis of language and sequential cognition: evidence from simulation, aphasia, and ERP studies. Brain and Language, $86,207-225$.

Dominey, P. F., Hoen, M. and Inui, T. (2006) A neurolinguistic model of grammatical construction processing. Journal of Cognitive Neuroscience, 18, 2088-2107.

Duffy, R. J. and Duffy, J. R. (1975) Pantomime recognition in aphasics. Journal of Speech and Hearing Research, 18, 115-132. 
Duffy, R. J. and Duffy, J. R. (1981) Three studies of deficits in pantomimic expression and pantomimic recognition in aphasia. Journal of Speech and Hearing Research, 24, 70-84.

Emmorey, K. D. (1989) Auditory morphological priming in the lexicon. Language and Cognitive Processes, 4, 73-92.

Fadiga, L., Craighero, L., Buccino, G. and Rizzolatti, G. (2002) Speech listening specifically modulates the excitability of tongue muscles: a TMS study. European Journal of Neuroscience, 15, 399-402.

Fadiga, L., Craighero, L., Fabbri Destro, M. et al. (2006a) Language in shadow. Social Neuroscience, $1,77-89$.

Fadiga, L., Craighero, L. and Roy, A. C. (2006b) Broca's area: a speech area? In Grodzinsky Y and Amunts, K (eds), Broca's Region, pp. 137-52. Oxford University Press, New York.

Fiebach, C. J. and Schubotz, R. I. (2006) Dynamic anticipatory processing of hierarchical sequential events: a common role for Broca's area and ventral premotor cortex across domains? Cortex, 42, 499-502.

Fitch, W. T., Hauser, M. D. and Chomsky, N. (2005) The evolution of the language faculty: clarifications and implications. Cognition, 97, 179-210.

Fogassi, L., Ferrari, P. F., Gesierich, B., Rozzi, S., Chersi, F. and Rizzolatti, G. (2005) Parietal lobe: from action organization to intention understanding. Science, 308, 662-667.

Friederici, A. D. (2006) Broca's area and the ventral premotor cortex in language: functional differentiation and specificity. Cortex, 42, 472-475.

Gainotti, G. and Lemmo, M. S. (1976) Comprehension of symbolic gestures in aphasia. Brain and Language, 3, 451-60.

Gall, F. J. (1822) Sur les functions du cerveau et sur celle de chacune de ses parties. Baillière, Paris.

Gallese, V., Fadiga, L., Fogassi, L. and Rizzolatti, G. (1996) Action recognition in the premotor cortex. Brain, 119, 593-609.

Gelfand, J. R. and Bookheimer, S. Y. (2003) Dissociating neural mechanisms of temporal sequencing and processing phonemes. Neuron, 38, 831-842.

Glosser, G., Wiener, M. and Kaplan, E. (1986) Communicative gestures in aphasia. Brain and Language, 27, 345-359.

Goldenberg, G. (1996) Defective imitation of gestures in patients with damage in the left or right hemispheres. Journal of Neurology, Neurosurgery and Psychiatry, 61, 176-80.

Grafton, S. T., Arbib, M. A., Fadiga, L. and Rizzolatti, G. (1996) Localization of grasp representations in humans by PET: 2. Observation compared with imagination. Experimental Brain Research, $112,103-111$.

Grafton, S. T., Fadiga, L., Arbib, M. A. and Rizzolatti, G. (1997) Premotor cortex activation during observation and naming of familiar tools. Neuroimage, 6, 231-236.

Grewe, T., Bornkessel, I., Zysset, S., Wiese, R., von Cramon, D. Y. and Schlesewsky, M. (2006) Linguistic prominence and Broca's area: the influence of animacy as a linearization principle. Neuroimage, 32, 1395-1402.

Grèzes, J. and Decety, J. (2002) Does visual perception of object afford action? Evidence from a neuroimaging study. Neuropsychologia, 40, 212-222.

Grèzes, J., Costes, N. and Decety, J. (1998) Top-down effect of strategy on the perception of human bioogical motion: a PET investigation. Cognitive Neuropsychology, 15, 553-582.

Grèzes, J., Fonlupt, P., Bertenthal, B., Delon-Martin, C., Segebarth, C. and Decety, J. (2001) Does perception of biological motion rely on specific brain regions? Neuroimage, 13, 775-785.

Grèzes, J., Armony, J. L., Rowe, J. and Passingham, R. E. (2003) Activations related to “mirror" and "canonical" neurones in the human brain: an fMRI study. Neuroimage, 18, 928-937.

Gruber, O., Inderfey, P., Steinmeiz, H. and Kleinschmidt, A. (2001) Dissociating neural correlates of cognitive components in mental calculation. Cerebral Cortex, 11, 350-359. 
Hamzei, F., Rijntjes, M., Dettmers, C., Glauche, V., Weiller, C. and Buchel, C. (2003) The human action recognition system and its relationship to Broca's area: an fMRI study. Neuroimage, 19, 637-644.

Hepp-Reymond, M. C., Husler, E. J., Maier, M. A. and Q1, H. X. (1994) Force-related neuronal activity in two regions of the primate ventral premotor cortex. Canadian Journal of Physiology and Pharmacology, 72, 571-579.

Iacoboni, M., Woods, R., Brass, M., Bekkering, H., Mazziotta, J. C. and Rizzolatti, G. (1999) Cortical mechanisms of human imitation. Science, 286, 2526-2528.

Johnson-Frey, S. H., Maloof, F. R., Newman-Norlund, R., Farrer, C., Inati, S. and Grafton, S. T. (2003) Actions or hand-object interactions? Human inferior frontal cortex and action observation. Neuron, 39, 1053-1058.

Koechlin, E. and Jubault, T. (2006) Broca's area and the hierarchical organization of human behavior. Neuron, 50, 963-974.

Koelsch, S., Gunter, T., Friederici, A. D. and Schroger, E. (2000) Brain indices of music processing: "non-musicians" are musical. Journal of Cognitive Neuroscience, 12, 520-541.

Kohler, E., Keysers, C. M., Umiltà, A., Fogassi, L., Gallese, V. and Rizzolatti, G. (2002) Hearing sounds, understanding actions: action representation in mirror neurons. Science, 297, 846-848.

Leroy-Gourhan, A. (1964) Le geste et la parole. Albin Michel, Paris.

Liberman, A. M. and Mattingly, I. G. (1985) The motor theory of speech perception revised. Cognition, 21, 1-36.

Liberman, A. M. and Wahlen, D. H. (2000) On the relation of speech to language. Trends in Cognitive Neuroscience, 4, 187-196.

Liberman, A. M., Cooper, F. S., Shankweiler, D. P. and Studdert-Kennedy, M. (1967) Perception of the speech code. Psychological Review, 74, 431-461.

Luders, H., Lesser, R. P., Hahn, J. et al. (1991) Basal temporal language area. Brain, 114, 743-754.

Luria, A. (1966) The Higher Cortical Function in Man. Basic Books, New York.

Maess, B., Koelsch, S., Gunter, T. C. and Friederici, A. D. (2001) Musical syntax is processed in Broca's area: an MEG study. Nature Neuroscience, 4, 540-545.

Matelli, M., Luppino, G. and Rizzolatti, G. (1985) Patterns of cytochrome oxidase activity in the frontal agranular cortex of macaque monkey. Behavioral Brain Research, 18, 125-137.

McManus, C. (2002) Right Hand, Left Hand. Harvard University Press, Cambridge, MA.

Mecklinger, A., Gruenewald, C., Besson, M., Magnié, M.-N. and Von Cramon, Y. (2002) Separable neuronal circuitries for manipulable and non-manipualble objects in working memory. Cerebral Cortex, 12, 1115-1123.

Murata, A., Fadiga, L., Fogassi, L., Gallese, V., Raos, V. and Rizzolatti, G. (1997) Object representation in the ventral premotor cortex (area F5) of the monkey. Journal of Neurophysiology, $78,2226-2230$.

Nelissen, K., Luppino, G., Vanduffel, W., Rizzolatti, G. and Orban, G. A. (2005) Observing others: multiple action representation in the frontal lobe. Science, 310, 332-336.

Ojemann, G. (1992) Localization of language in frontal cortex. In Chauvel, P. and Delgado-Escueta, A. V. (eds), Advances in Neurology, Vol. 57, pp. 361-368. Raven Press, New York.

Ojemann, G., Ojemann, J., Lettich, E. and Berger, M. (1989) Cortical language localization in left, dominant hemisphere. An electrical stimulation mapping investigation in 117 patients. Journal of Neurosurgery, 71, 316-326.

Penfield, W. and Roberts, L. (1959) Speech and Brain Mechanisms. Princeton University Press, Princeton, NJ.

Petrides, M. (2006) Broca's area in the human and the nonhuman primate brain. In Grodzinsky, Y. and Amunts, K. (eds), Broca's Region, pp. 31-46. Oxford University Press, New York. 
Petrides, M. and Pandya, D. N. (1997) Comparative architectonic analysis of the human and the macaque frontal cortex. In Boller, F. and Grafman, J. (eds), Handbook of Neuropsychology, Vol. IX, pp. 17-58. Elsevier, New York.

Pulvermuller, F., Huss, M., Kherif, F., Moscoso del Prado Martin, F., Hauk, O. and Shtyrov, Y. (2006) Motor cortex maps articulatory features of speech sounds. Proceedings of the National Academy of Sciences of the USA, 103, 7865-7870.

Ranganath, C., Johnson, M. and D’Esposito, M. (2003) Prefrontal activity associated with working memory and episodic long-term memory. Neuropsychologia, 41, 378-89.

Rizzolatti, G. and Arbib, M. A. (1998) Language within our grasp. Trends in Neurosciences, 21, 188-194.

Rizzolatti, G. and Fadiga, L. (1998) Grasping objects and grasping action meanings: the dual role of monkey rostroventral premotor cortex (area F5). In Bock G. R. and Goode, J A. (eds), Sensory Guidance of Movement, Novartis Foundation Symposium, pp. 81-103. Wiley, Chichester.

Rizzolatti, G., Camarda, R., Fogassi, L., Gentilucci, M., Luppino, G. and Matelli, M. (1988) Functional organization of inferior area 6 in the macaque monkey: II. Area F5 and the control of distal movements. Experimental Brain Research, 71, 491-507.

Rizzolatti, G., Fadiga, L., Gallese, V. and Fogassi, L. (1996a) Premotor cortex and the recognition of motor actions. Cognitive Brain Research, 3, 131-141.

Rizzolatti, G., Fadiga, L. and Matelli, M. (1996b) Localization of grasp representation in humans by PET: 1. Observation versus execution. Experimental Brain Research, 111, 246-252.

Rizzolatti, G., Fogassi, L. and Gallese, V. (2002) Motor and cognitive functions of the ventral premotor cortex. Current Opinion in Neurobiology, 12, 149-154.

Saygin, A. P., Wilson, S. M., Hagler, D. J. Jr, Bates E. and Sereno, M. I. (2004) Point-light biological motion perception activates human premotor cortex. Journal of Neurosciences, 24, 6181-618.

Schaffler, L., Luders, H. O., Dinner, D. S., Lesser, R. P. and Chelune, G. J. (1993) Comprehension deficits elicited by electrical stimulation of Broca's area. Brain, 116, 695-715.

Schubotz, R. I. and von Cramon, D. Y. (2003) Functional-anatomical concepts of human premotor cortex: evidence from fMRI and PET studies. Neuroimage, 20 (Suppl. 1), 120-131.

Schubotz, R. I. and von Cramon, D. Y. (2004) Sequences of abstract nonbiological stimuli share ventral premotor cortex with action observation and imagery. Journal of Neuroscience, 24, 5467-5474.

Schubotz, R. I., Sakreida, K., Tittgemeyer, M. and von Cramon, D. Y. (2004) Motor areas beyond motor performance: deficits in serial prediction following ventrolateral premotor lesions. Neuropsychology, 18, 638-645.

Stromswold, K. (1995) The cognitive and neural bases of language acquisition. In Gazzaniga, M. (ed.), The Cognitive Neurosciences, pp. 855-870. MIT Press, Cambridge, MA.

Tranel, D., Kemmerer, D., Damasio, H., Adolphs, R. and Damasio, A. R. (2003) Neural correlates of conceptual knowledge for actions. Cognitive Neuropsychology, 20, 409-432.

Umiltà, M. A., Kohler, E., Gallese, V. et al. (2001) I know what you are doing: a neurophysiological study. Neuron, 31, 155-165.

Wernicke, C. (1874) Der aphasische Symptomencomplex. Eine psychologische Studie auf anatomischer Basis. Springer-Verlag, Berlin.

Wilson, S. M., Saygin, A. P., Sereno, M. I. and Iacoboni, M. (2004) Listening to speech activates motor areas involved in speech production. Nature Neuroscience, 7, 701-702.

Wolfensteller, U., Schubotz, R. I. and von Cramon, D. Y. (2004) "What" becoming "where": functional magnetic resonance imaging evidence for pragmatic relevance driving premotor cortex. Journal of Neuroscience, 24, 10431-10439. 